\title{
Autosomal recessive spastic paraplegia type 56
}

INSERM

\section{Source}

INSERM. (1999). Orphanet: an online rare disease and orphan drug data base. Autosomal recessive spastic paraplegia type 56. ORPHA:320411

A rare form of hereditary spastic paraplegia characterized by delayed walking, toe walking, unsteady and spastic gait, hyperreflexia of the lower limbs, and extensor plantar responses. Upper limbs spasticity and dystonia, subclinical axonal neuropathy, cog nitive impairment and intellectual disability have also been associated. 